\title{
Experiences and coping strategies of perinatally bereaved mothers with the loss
}

\author{
Eniola Sarat Onaolapo*, Edward Appiah Boateng, Felix Apiribu and \\ Veronica Millicent Dzomeku \\ Department of Nursing, Kwame Nkrumah University of Science and Technology (KNUST), Kumasi, Ghana.
}

Received 18 February, 2020; Accepted 10 April, 2020

\begin{abstract}
This study explored the experiences, coping strategies, and support systems available for perinatally bereaved mothers. A descriptive phenomenological design was employed to explore lived experiences of perinatally bereaved mothers and saturation was reached with the $12^{\text {th }}$ participant. Participants were recruited through purposive sampling and data was collected by in-depth, individual and face-to-face interviews. Data analysis was guided by Colaizzi's method. From the results, four main themes emerged - deprived care, immediate reactions to the loss, painful reminders of the loss, and coping strategies. Participants felt that deprived care contributed to their loss, and continuous support required in managing it was mostly lacking. Participants employed various strategies in coping with the loss, including self-motivation and religious beliefs. Thus, clinicians need to be more vigilant and ensure that mothers and neonates receive adequate care. Increasing awareness of the support needs of perinatally bereaved mothers could rally emotional support for them during grieving moments.
\end{abstract}

Key words: Perinatal loss, perinatal bereavement, bereaved mothers, experiences, coping strategies, Kumasi, Ghana.

Abbreviations: CH, Christian; MU, Muslim; JHS, Junior High School; SHS, Senior High School.

\section{INTRODUCTION}

Perinatal loss is a sad, painful and unexpected experience not only for those who conceived but the entire family and is of a major global concern (Wardlaw et al., 2014; Gold et al., 2016; Ibrahim et al., 2016; Annan and Asiedu, 2018; Fenstermacher and Hupcey, 2019; Gandino et al., 2019). The World Health Organization (2019) defines perinatal mortality as the number of stillbirths and deaths that occur in the first week of life while others include miscarriage and neonatal deaths up to 28 days after birth in the definition of perinatal loss (Meredith et al., 2017; Moore and Côté-Arsenault, 2018; Fenstermacher and Hupcey, 2019; Gandino et al., 2019). It is estimated that over 6.3 million cases of perinatal loss occur in the world annually, majority of which occur in low- and middle-income countries (LMICs) (WHO, 2006; Ibrahim et al., 2016; Meredith et al., 2017; Paudel et al., 2018), placing a huge burden on health systems and families (Caelli et al., 2002). Its prevalence varies by

*Corresponding author. E-mail: ennystar1996@yahoo.com. Tel: +233 (0)50 1347632.

Author(s) agree that this article remain permanently open access under the terms of the Creative Commons Attribution License 4.0 International License 
geographical location but is highest in West and Central Africa, where the risk of neonatal mortality is 10 times higher than the rates in many high-income countries (Wardlaw et al., 2014; Annan and Asiedu, 2018). In fact, neonatal death is estimated to account for approximately $50 \%$ of child under-five mortality in Ghana where this study was conducted (Ghana Health Service, 2019).

Perinatally bereaved mothers and fathers respond to the loss differently (Cacciatore et al., 2008). Mothers are believed to be at an increased risk of severe grief following a perinatal loss, as compared to fathers, as the mother tends to recognize the baby as an extension of herself (Caelli et al., 2002; Michonet al., 2003; Cacciatore et al., 2008; Song et al., 2010). Thus, the support needs of perinatally bereaved fathers seem to be mostly ignored (Clossick, 2016; Kalu et al., 2018). Psychological problems, including anxiety, complicated grief and depression have been reported among mothers experiencing perinatal loss and these could result in increased morbidity (Cacciatore et al., 2008; Gold et al., 2016). Low self-esteem has also been reported among perinatally bereaved mothers, leading to these women doubting their ability to carry another pregnancy to term or to avoid another perinatal loss (Caelli et al., 2002; Meert et al., 2005; Hendrickson, 2009; Meredith et al., 2017; Wonch Hillet al., 2017). The risk of psychosocial and psychiatric problems increases while an increased risk of mortality, especially from cardiovascular diseases, has also been reported among perinatally bereaved mothers (Maciejewskiet al., 2007; Prigerson and Maciejewski, 2008; Hvidtjørn et al., 2016).

Perinatally bereaved mothers have expressed their wish for people to acknowledge their losses, be considerate and sensitive, and give them a listening ear as well as psychological and emotional support in their critical period (Caelli et al., 2002). Unfortunately, they do not always get the needed support and this affects their emotional health and relationships, including that with their partners and/or other children (Cumming et al., 2007; Forhan, 2010; Murphyet al., 2012). Indeed, many clinicians may not feel confident to adequately manage and provide bereavement support to aggrieved parents (Kalu et al., 2018). To reduce he risk of death, psychosocial and psychiatric problems after perinatal loss, clinicians need to appreciate the grieving process and identify symptoms of possible complicated grief in mothers and other family members for early identification and to be managed promptly by providing adequate emotional support (Gijzenet al., 2016). However, there seems to be no well-coordinated guideline or support system for managing perinatally bereaved mothers and their families in Ghana. A lack of information on their experiences could have contributed to this. This study was, therefore, conducted to explore experiences, coping strategies, and support systems available for perinatally bereaved mothers. This would contribute to developing interventions that would be beneficial to mothers and families experiencing perinatal loss within the country and other similar settings. The research findings would aid clinicians to better understand and support affected mothers psychologically and emotionally and to provide evidence-based information to guide clinical practice.

\section{MATERIALS AND METHODS}

\section{Study design and setting}

A descriptive phenomenological design was employed to explore lived experiences and coping strategies of perinatally bereaved mothers and saturation was reached with the $12^{\text {th }}$ participant. This design was chosen because of its ability to contribute to a deeper understanding of the lived experiences of women through the close examination of their unique individual experiences (Starks and Brown Trinidad, 2007). The study was conducted in one of the leading hospitals in the country that provides specialist services in several areas, including Obstetrics and Gynaecology, and has relatively developed neonatal intensive care services.

\section{Sampling procedures}

Purposive sampling method was used to select perinatally bereaved mothers for this study. The midwife in charge of the neonatal intensive care unit was approached by all researchers (after ethical approval had been given by the Review Board) and the aim of the study was explained to her, after which she aided in the identification of perinatally bereaved mothers. ESO then approached all potential participants and explained the aim of the study to them and discussed their possible inclusion. All mothers who were approached agreed to take part in the study and were made to sign a consent form before being interviewed. Five of the participants had come to the unit to follow up on death certificates of their neonates while the remaining seven were still on admission at the hospital. Provision was made for any mother who would become emotionally traumatised during the interview to see the clinical psychologist in the hospital. However, no such event was encountered.

\section{Data collection}

In-depth, individual, face-to-face, semi-structured interviews were conducted using an interview guide. The interview guide covered areas including participants' profile, general experiences with perinatal loss, support systems available to perinatally bereaved mothers as well as their coping strategies. All interviews were carried out by ESO within the hospital setting, with privacy ensured and lasting between 30 and 45 min respectively. Following each interview session, field notes were taken to detail observations and mannerisms that were not captured through the audio recording. All interview sessions were conducted in the English language and were audio-recorded, with each participant's consent. There were no repeat interviews.

\section{Data processing and analysis}

Data collection was concurrent with transcription and each digitally recorded interview session was listened to and carefully transcribed soon after the session. Analysis of data for this study was guided by the Colaizzi method (Colaizzi, 1978; Wirihana et al., 2018). Transcripts were read while listening to the audio version to ensure accuracy. Transcripts were returned to the seven participants who were still on admission at the hospital for comments and possible 
correction and deletion of personal information but none of the seven felt the need to change sections of their respective transcripts. Each transcript was then read multiple times and coded independently by ESO and EAB. The field notes were also read to aid contextualisation of various participant accounts. Significant statements about participants' experiences with perinatal loss were extracted and meanings formulated out of these statements. This was done concurrently with data collection, allowing subsequent interview sessions to focus on exploring emerging themes further. Series of meetings were held among all researchers to aggregate the meanings into theme clusters. The theme clusters were reviewed, summarized, and classified into themes according to similarities and appropriateness. This continued until all authors came to an agreement that themes had been adequately explored for the aim of this study and so there was no need for further data collection (O'Reilly and Parker, 2013).

\section{Trustworthiness}

This part of the work describes approaches that were utilized to promote trustworthiness of the study. ESO and EAB independently coded the data while all researchers met frequently to discuss emerging themes and finalise them. This ensured investigator triangulation and thorough report of findings (Korstjens and Moser, 2018). Direct quotes of participants have also been included in the report to enhance credibility and confirmability of the study findings (Noble and Smith, 2015; Korstjens and Moser, 2018). Member checks was also done by sending transcripts to participants who were available for review, and also to enhance credibility of the findings (Thomas, 2017).

\section{Ethical considerations}

Ethics approval, with reference number CHRPE/AP/127/19, was obtained from the Committee on Human Research, Publication and Ethics (CHRPE) of Kwame Nkrumah University of Science and Technology. Participants were assured of anonymity, privacy and confidentiality of their responses as well as the voluntary nature of participation in this study. All participants consented to participate in the research. Pseudonyms were used on the transcripts and in this paper to ensure anonymity. The number of days each participant's neonate survived has also been added to the pseudonym after each quote.

\section{RESULTS}

Twelve (12) perinatally bereaved mothers participated in this study. Their characteristics have been presented in (Table 1). Four main themes were derived from analysis of data generated from this study (Table 2).

\section{Deprived care}

This theme described perceptions of participants on healthcare services rendered to them during the period leading to the perinatal loss. Participants generally felt that care was not provided when it was needed or in a safe and effective manner. This, they felt, contributed to the loss of their babies and described it as a drastic experience for them. There were two sub-themes under this theme-poor communication and negligence.

\section{Poor communication}

Participants generally felt that communication between them and the clinicians was inadequate. This led to seeming tension between them and the clinicians, making it difficult for them to express their feelings or communicate their needs, even when they felt their neonates needed attention because of deteriorating condition. Thus, participants could not get attention from clinicians as they would have expected, leading them to conclude that poor communication contributed to the poor outcomes of the care that they received.

I could not establish rapport with her [nurse] and even when I realized that there was something wrong with the baby's eye which made me scared, I could not tell her because there was tension between us (Adwoa, 1 day).

They [clinicians] do not get to communicate with us. So, when my baby was having a [high] temperature, I could not inform them because there was no communication at all (Yaa, 1 day).

\section{Negligence}

This second sub-theme described moments when participants felt that clinicians had neglected their duty of care or did not demonstrate enough enthusiasm. While some participants could not communicate their requests for care to clinicians because of seeming tension, some of those who did felt that clinicians either failed to act appropriately or delayed in providing the appropriate care for their babies, as expected.

I asked her [nurse] about the oxygen the doctor requested her to administer to my baby. I remember that terrible look on that nurse's face - she rolled her eyes at me and walked away. She wasted so much time in bringing the oxygen (Akosua, 1day).

My baby became so hot to touch so I went to the nurses and told them to please call the doctor for me. One of them shouted at me that I complained a lot and I should go back, another one said she's eating while the last one was fidgeting with her phone (Akua, 5days).

\section{Immediate reactions to the loss}

This theme described responses of participants after being informed about the death of their neonates. Words such as "painful", "miserable", "indescribable", "hurting", "sad" and "guilt feeling" were mostly used by participants to describe their feelings after the loss while a few others 
Table 1. Participants' profile.

\begin{tabular}{lclllcc}
\hline Name & Age (years) & Religion & Education level & Occupation & Age of neonate (days) & Previous perinatal loss \\
\hline Adwoa & 29 & Christian & Tertiary & Trader & 1 & None \\
Abena & 27 & Christian & SHS & Housewife & 2 & None \\
Akua & 35 & Christian & Tertiary & Teacher & 5 & None \\
Yaa & 32 & Christian & SHS & Hairdresser & 1 & None \\
Afia & 26 & Christian & Tertiary & Trader & 5 & Yes \\
Ama & 31 & Christian & JHS & Trader & 1 & None \\
Akosua & 33 & Muslim & JHS & Unemployed & 1 & None \\
Maama & 38 & Muslim & SHS & Housewife & 5 & None \\
Nana & 28 & Muslim & SHS & Unemployed & 5 & None \\
Naana & 29 & Muslim & Tertiary & Trader & 5 & None \\
Esi & 27 & Christian & Tertiary & Teacher & 5 & None \\
Serwaa & 32 & Christian & Tertiary & Trader & 5 & \\
\hline
\end{tabular}

JHS: Junior High School; SHS: Senior High School.

Table 2. Themes and subthemes generated from the data.

\begin{tabular}{lll}
\hline & Theme & Sub-theme \\
\hline Theme 1 & Deprived care & Poor communication; Negligence \\
Theme 2 & Immediate reaction to the loss & \\
Theme 3 & Painful reminders of the loss & \\
Theme 4 & Coping strategies & \\
\hline
\end{tabular}

described their reactions with words such as "numbness", "disbelief", or "self-pity". For one participant, her painful reaction was worsened by memories of a previous perinatal loss while the others felt that carrying the pregnancy for its entire duration and losing the baby after a few days was the most traumatising experience one could have.

After the doctor told me my baby is dead, I ran out of the ward like a mad woman in tears and I began to ask God why I have delivered twice and both died within seven days of life (Afia, 5 days).

Everyone is going home with his or her baby and you alone, you go home empty-handed, it is[the] most traumatic experience that can ever happen to someone, it is very sad and painful. I do not even want to think about it, I cannot put it into words (Adwoa, 1day).

Some participants made statements that suggested that news about the perinatal loss caused them to lose touch with reality, not being fully aware of how they reacted to the loss. They had to rely on accounts of their relatives to appreciate their immediate reactions to the loss and these were typical of denial of the loss or a state of shock and disbelief with visual and auditory hallucinations.

My mother told me that I kept seeing my baby and hearing my baby cry even though the baby was dead (Yaa, 1 day).

My sister told me that I kept going to prepare the baby's bath, or sometimes I went to the baby's crib to see if the baby was sleeping well (Afia, 5 days).

Another participant hoped that the loss could somehow be reversed and took steps to pursue this, including following advice by her religious leader. However, she realised, painfully, that it was not possible for the loss to be reversed.

I went to church and I was given anointing oil to pray with [so] that the baby will come back to life...but nothing happened (Serwaa, 5days).

A few other participants described their initial reactions to the loss of their babies as numb, not really appreciating the magnitude of what had happened to them until other external circumstances 'forced' them to consider the hard realities that they had to deal with. Such circumstances usually led them to shed tears for the loss of their babies for the first time.

At that time, I really did not feel anything, I gave everything to God...they were twins. When neighbours came to ask where my other baby was, that made me cry (Akua, 5 days). 
At that moment nothing happened to me. It was at the reception where I saw some mothers breastfeeding their babies then I began to cry; that troubled me (Nana, 5 days).

Another common reaction among perinatally bereaved mothers in this study was the feeling of guilt - that they, somehow, contributed to the death of their neonate. They reflected on incidents leading to the loss and wondered whether the outcome would have been different had they chosen to act differently.

If I had rushed my baby back to the hospital the moment I observed some changes, I would not have lost my baby (Akua, 5 days).

If I had taken my baby to a different hospital the moment I noticed the doctors and the nurses' negligence, maybe my baby would not have died (Naana, 5 days).

\section{Painful reminders of the loss}

This theme described incidents that served to remind participants of their loss. Perinatal loss left a permanent scar in the lives of participants and their families. Although the impact of this experience was expected to wane with time, there seemed to be occasional or constant reminders of this loss to bereaved mothers, bringing back fresh memories of the pain associated with the loss. Sometimes, this was in the form of their partners withdrawing their support and creating seeming hostility in the relationship, especially where there was childlessness since the loss. At other times, perinatally bereaved mothers were reminded of their loss when they saw other babies or other reminders associated with the pregnancy that resulted in a perinatal loss.

It was not easy at all. I had a previous [perinatal] loss, and this again! At a point my husband started frustrating me, coming back home late at night...he even threatened to bring in another woman as a wife. (Afia, 5 days).

After one has gone through a caesarean section and the baby dies within seven days of life, it is a painful experience compared to normal delivery because whenever you see the scar, when bathing or naked, what is the testimony for that scar? No testimony! I see the scar there but there is nothing to console me. I feel very bad and miserable (Esi, 5days).

You meet some people with their children, everybody with their baby, it is painful, it brings back the memories (Akua, 5 days).

\section{Coping strategies}

Coping strategies described efforts employed by perinatally bereaved mothers or their significant others to manage their traumatic experience. Participants described various strategies that helped them to cope, including self-motivation or diversional activities.

All mothers have to be strong for themselves especially during their loss because whatever loss or pain or tragedy we are experiencing we would always get through it. I know it hurts but my Allah will do another one, I know (Maama,5days).

...l go swimming and meet new people and laugh and share jokes...these things make me feel okay (Serwaa, 5days).

Others relied on their religious or cultural beliefs about death and dying to manage the perinatal loss. Those who relied on their religious beliefs surmised that God/Allah knows best and that experiencing perinatal loss was meant to serve a purpose in their lives in the short or long term. In terms of cultural orientation, some participants had come to believe that perinatal loss is a common occurrence and consoled themselves with the fact that they were not the only individuals to have ever experienced it.

I believe God has a purpose for everything, he allowed this to happen for a reason (Esi, 5days).

Some women from my village believe that losing a baby is a generational occurrence in my family...they said my sister also lost one, my mother also lost one, my mother's elder sister also lost one (Ama, 1 day)

Other participants relied on support from their significant others in dealing with the loss.

I had some set of friends...they comforted me; they were there for me. They encouraged me not to be sad (Akua, 5days).

I have the most amazing and supportive husband in the whole world...he did not let me feel bad. He is so funny and dramatic that all his dramatic acts in the house make me forget my loss (Naana, 5days).

Yet, not all participants had utmost support from their significant others in managing their loss. Instead, they were made to feel that they had, somehow, contributed to the loss, making it more difficult for them to manage it.

I am a third wife so the other wives mocked me so bad that at some point I felt like committing suicide...they all acted as if I intentionally killed the baby myself. People's attitude sometimes can make someone's situation worse (Abena, 2days).

In summary, experiences of perinatally bereaved mothers in this study fell under four main themes and these have 
been presented above. They generally felt that their neonates were deprived of the needed care, contributing to their demise. Their immediate reactions to the loss as well as occasional or constant reminders of the loss have also been described. Finally, strategies employed in dealing with the loss have been described.

\section{DISCUSSION}

This study aimed at exploring the experiences of perinatally bereaved mothers regarding their loss. The study categorised participants' experiences into four main themes - deprived care, immediate reactions to the loss, painful reminders of the loss, and coping strategies.

Many participants felt that poor communication between them and clinicians as well as negligence contributed to the death of their neonates. Indeed, similar feelings of mismanagement by clinicians or a lack of enthusiastic care contributing to perinatal loss have been reported elsewhere (Caelli et al., 2002). Such feelings are likely to engender anger and feelings of mistrust towards clinicians among perinatally bereaved mothers.

Perinatally bereaved mothers tend to feel guilty, blaming themselves for not being careful enough or taking appropriate actions that would have prevented the death, even when they are told that they are not to blame (Caelli et al., 2002; Frost et al., 2007; Gausia et al., 2011). Participants in this current study were not exempted from such guilt feelings. This feeling of guilt is compounded when others infer that bereaved mothers are to blame and, in some cases, seek to punish them for that. In an Ethiopian study, women who had experienced multiple perinatal losses were blamed, mistreated, or even divorced (Sisayet al., 2014). Although most bereaved mothers in our study did not report being blamed, stigmatised or maltreated for their loss, one participant shared how her husband had threatened to bring in another woman as a wife should she fail to have a successful pregnancy and a positive outcome. Such feelings of guilt have the potential to affect their selfesteem, leading them to question their capacity to carry a pregnancy to term and/or mother a child, and this is strongly brought to the fore when another pregnancy occurs (Caelli et al., 2002; Meredith et al., 2017; Moore and Côté-Arsenault, 2018). Specific interventions to manage such potential situations have been advocated for (Caelli et al., 2002; Kelley and Trinidad, 2012; Meredith et al., 2017; Moore and Côté-Arsenault, 2018). Guilt has also been associated with depression among perinatally bereaved mothers (Gausia et al., 2011). Continuous reassurance of bereaved mothers that they did not cause the death helps in dealing with feelings of guilt (Kelley and Trinidad, 2012). Denial has also been reported among some perinatally bereaved mothers as part of their initial reactions to the loss (Kalu et al., 2018). Some of our participants made statements that reflected denial.
Perinatally bereaved mothers live with the pain of the loss throughout life as moments and situations bring back the memory (Rybarik, 2000; Caelli et al., 2002; Kelley and Trinidad, 2012). Sometimes, seeing other mothers with their babies or hearing other babies cry make the loss more unbearable for bereaved mothers (Clossick, 2016). Several coping strategies have been employed by perinatally bereaved mothers or their clinicians in dealing with the loss(Caelli et al., 2002; Meredith et al., 2017). A key coping strategy is for the bereaved mother to motivate themselves rather than rely solely on external support. Participants in this current study displayed signs of hope in their narratives of their painful and negative experiences. Some stated that they had more moments of happiness and less sad ones, with self-motivation being the bedrock on which this was attained. Also, some of our participants got involved in activities that they felt were helpful in managing their grief whereas others engaged in diversional activities such as swimming.

While the loss stays with the bereaved mother for her lifetime, those around them tend to forget about it after a couple of months and expect the bereaved mother to do same (Gensch and Midland, 2000; Caelli et al., 2002; Kelley and Trinidad, 2012). In fact, in many settings in Africa, bereaved mothers are discouraged from openly mourning their loss, with the belief that either the neonate is not fully considered as a human being or grieving for the loss would reduce the chances of a future pregnancy (Kelley and Trinidad, 2012; Sisay et al., 2014; Ibrahim et al., 2016; Paudel et al., 2018). Miscarriage, which is included in the definition of perinatal loss, was not even clearly considered as a source of bereavement until in the 1980s (Frost et al., 2007). Consequently, bereaved mothers are less likely to receive formal support in dealing with their loss, both in the clinical setting or community. Yet, support from significant others, clinicians, and the bereaved mother's social network have been effective in managing perinatal loss (Rybarik, 2000; Gijzen et al., 2016). Our participants narrated that support, in the form of encouragement, advice and reassurance came from their families and friends. This has been reported as the main form of social support that perinatally bereaved mothers receive, reducing levels of maternal anxiety and depression (Cacciatore et al., 2008).

There were no reports of formal support systems that exist for perinatally bereaved mothers in this study although our participants inferred that clinicians provided some form of emotional support for them following their loss. Communication is a central part of support rendered to perinatally bereaved mothers and their families (Kelley and Trinidad, 2012) and perinatally bereaved mothers appreciate availability and clarity of information from clinicians around the time when the loss occurs (Gravensteen et al., 2013). However, it is always challenging for the new clinician as they do not always know what to say or do under such circumstances (Kalu et al., 2018). Indeed, not all clinicians are confident about 
managing bereaved mothers. This results in perinatally bereaved mothers feeling alone and unsupported by clinicians. Grieving among perinatally bereaved mothers is complex and more individualised, making provision of effective support more challenging for clinicians, particularly midwives (Cacciatore et al., 2008; Kalu et al., 2018). Clinical experiences of caring for such mothers enhance confidence (Rybarik, 2000).Non-verbal support, including holding hands or sitting by the client without saying a word has been deemed appropriate support (Kelley and Trinidad, 2012).

\section{Limitation}

All interviews were conducted in the English language, implying that experiences of those who could not speak the language may have been excluded. However, with adult literacy rate in Ghana increasing from 57\% in 2000 to $79 \%$ in 2018 (The World Bank, 2019), only few perinatally bereaved mothers may have been excluded based on language.

\section{Conclusion}

Perinatal loss is a common and painful experience for the bereaved mother, her family, clinicians and the community and efforts at reducing its occurrence through the provision of timely and adequate care to women during childbirth is needed. The experiences of the bereaved mother are not clearly understood. While the memories of the loss and its subsequent repercussions could remain with the bereaved mother for a lifetime, the significance of the loss diminishes among family and the society within a shorter period. Clinicians are not always adequately prepared on how to provide support to these mothers with complex but more individualistic needs. This study utilised a descriptive phenomenological design to explore the lived experiences of perinatally bereaved mothers in a context where little was known about the concept. The findings of this study could serve as a guide for formulating policies that could improve the management and support systems available to perinatally bereaved mothers. Improved communication between clinicians and perinatally bereaved mothers is urgently recommended, especially around the time of the loss. Formal bereavement services could bridge the communication gap between clinicians and mothers, erasing the perception of a lack of support from clinicians. This could also address the emotional as well as psychological needs of bereaved mothers and their families. Increasing awareness of the support needs of perinatally bereaved mothers could rally emotional support for them during the grieving moments. Although clinicians increase their expertise in managing perinatal losses with time, a formal training on managing such sensitive situations could be life-changing for perinatally bereaved mothers. Exploring the experiences of perinatally bereaved fathers could also contribute to a deeper understanding of how perinatal loss affects families.

\section{CONFLICTS OF INTERESTS}

The authors have not declared any conflict of interests.

\section{ACKNOWLEDGEMENTS}

The authors are grateful to the perinatally bereaved mothers who shared their experiences with them.

\section{REFERENCES}

Annan GN, Asiedu Y (2018). Predictors of Neonatal Deaths in Ashanti Region of Ghana: A Cross-Sectional Study. Advances in Public Health, 2018.

Cacciatore J, DeFrain J, Jones KL, Jones H (2008). Stillbirth and the couple: A gender-based exploration.. Journal of Family Social Work $11(4): 351-372$.

Caelli K, Downie J, Letendre A (2002). Parents' experiences of midwife-managed care following the loss of a baby in a previous pregnancy. Journal of Advanced Nursing 39(2):127-136.

Clossick E (2016). The impact of perinatal loss on parents and the family. Journal of Family Health 26(3):11-15.

Colaizzi PF (1978). Psychological research as the phenomenologist views it. In R. Vale and M. King (Eds.), Existential-Phenomenological Alternatives for Psychology. New York: Oxford University Press.

Cumming G, Klein S, Bolsover D, Lee A, Alexander D, Maclean M, Jurgens $J$ (2007). The emotional burden of miscarriage for women and their partners: trajectories of anxiety and depression over 13 months. BJOG: An International Journal of Obstetrics and Gynaecology 114(9): 1138-1145.

Fenstermacher KH,Hupcey JE (2019). Support for Young Black Urban Women After Perinatal Loss. MCN: The American Journal of Maternal/Child Nursing 44(1):13-19.

Forhan M (2010). Doing, being, and becoming: A family's journey through perinatal loss. American Journal of Occupational Therapy 64(1):142-151.

Frost J, Bradley H, Levitas R, Smith L,Garcia J (2007). The loss of possibility: scientisation of death and the special case of early miscarriage. Sociology of Health and Illness 29(7):1003-1022.

Gandino G, Bernaudo A, Di Fini G, Vanni I, Veglia F (2019). Healthcare professionals' experiences of perinatal loss: A systematic review. Journal of Health Psychology 24(1):65-78 doi:10.1177/1359105317705981

Gausia K, Moran AC, Ali M, Ryder D, Fisher C, Koblinsky M (2011). Psychological and social consequences among mothers suffering from perinatal loss: perspective from a low income country. BMC Public Health 11(1):451.

Gensch BK, Midland D (2000). When a baby dies: A standard of care. Illness, Crisis and Loss 8(3):286-295.

Ghana Health Service. (2019). Newborn Care Programme. Retrieved from https://www.ghanahealthservice.org/newborn/

Gijzen S, L'Hoir MP, Boere-Boonekamp MM,Need A (2016). How do parents experience support after the death of their child? BMC Pediatrics 16(1):204.

Gold KJ, Leon I, Boggs ME, Sen A (2016). Depression and posttraumatic stress symptoms after perinatal loss in a populationbased sample. Journal of Women's Health 25(3):263-269.

Gravensteen IK, Helgadóttir LB, Jacobsen EM, Rådestad I, Sandset

PM, Ekeberg $\varnothing$ (2013). Women's experiences in relation to stillbirth and 
risk factors for long-term post-traumatic stress symptoms: a retrospective study. BMJ 3(10):e003323.

Hendrickson KC (2009). Morbidity, mortality, and parental grief: a review of the literature on the relationship between the death of a child and the subsequent health of parents. Palliative and Supportive Care 7(1):109-119.

Hvidtjørn D, Wu C, Schendel D, Thorlund Parner E,Brink Henriksen T (2016). Mortality in mothers after perinatal loss: a population-based follow-up study. BJOG: An International Journal of Obstetrics and Gynaecology 123(3):393-398.

Ibrahim A, Maya ET, Donkor E, Agyepong IA,Adanu RM (2016). Perinatal mortality among infants born during health user-fees (Cash and Carry) and the national health insurance scheme (NHIS) eras in Ghana: a cross-sectional study. BMC Pregnancy and Childbirth 16(1):385.

Kalu FA, Coughlan B, Larkin P (2018). A mixed methods sequential explanatory study of the psychosocial factors that impact on midwives' confidence to provide bereavement support to parents who have experienced a perinatal loss. Midwifery 64:69-76. doi:https://doi.org/10.1016/j.midw.2018.06.011

Kelley MC,Trinidad SB (2012). Silent loss and the clinical encounter: parents' and physicians' experiences of stillbirth-a qualitative analysis. BMC Pregnancy and Childbirth 12(1):137.

Korstjens I, Moser A (2018). Series: Practical guidance to qualitative research. Part 4: Trustworthiness and publishing. European Journal of General Practice 24(1):120-124. doi:10.1080/13814788.2017.1375092

Maciejewski PK, Zhang B, Block SD, Prigerson HG (2007). An empirical examination of the stage theory of grief. JAMA 297(7):716-723.

Meert KL, Thurston CS,Briller SH (2005). The spiritual needs of parents at the time of their child's death in the pediatric intensive care unit and during bereavement: A qualitative study. Pediatric Critical Care Medicine 6(4):420-427.

Meredith P, Wilson T, Branjerdporn G, Strong J, Desha L (2017). "Not just a normal mum": a qualitative investigation of a support service for women who are pregnant subsequent to perinatal loss. BMC Pregnancy and Childbirth 17(1):6. doi:10.1186/s12884-016-1200-9

Michon B, Balkou S, Hivon R, Cyr C (2003). Death of a child: parental perception of grief intensity-end-of-life and bereavement care. Paediatrics and Child Health 8(6):363-366.

Moore SE,Côté-Arsenault D (2018). Navigating an Uncertain Journey of Pregnancy After Perinatal Loss. Illness, Crisis and Loss, 26(1):58-74.

Murphy FA, Lipp A,Powles DL (2012). Follow-up for improving psychological well being for women after a miscarriage. Cochrane Database of Systematic Reviews(3).

Noble H, Smith J (2015). Issues of validity and reliability in qualitative research. Evidence-Based Nursing 18(2):34-35.

O'reilly M,Parker N (2013). 'Unsatisfactory Saturation': a critical exploration of the notion of saturated sample sizes in qualitative research. Qualitative Research 13(2):190-197.

Paudel M, Javanparast S, Dasvarma G,Newman L (2018). Religiocultural factors contributing to perinatal mortality and morbidity in mountain villages of Nepal: Implications for future healthcare provision. PloS ONE 13(3): e0194328.

Prigerson HG, Maciejewski PK (2008). Grief and acceptance as opposite sides of the same coin: setting a research agenda to study peaceful acceptance of loss. The British Journal of Psychiatry 193(6):435-437.
Rybarik F (2000). Perinatal bereavement. Illness, Crisis and Loss 8(3):221-226.

Sisay MM, Yirgu R, Gobezayehu AG, Sibley LM (2014). A qualitative study of attitudes and values surrounding stillbirth and neonatal mortality among grandmothers, mothers, and unmarried girls in rural Amhara and Oromiya regions, Ethiopia: unheard souls in the backyard. Journal of Midwifery and Women's Health 59(s1):S110S117.

Song J, Floyd FJ, Seltzer MM, Greenberg JS, Hong J (2010). LongTerm Effects of Child Death on Parents' Health-Related Quality of Life: A Dyadic Analysis. Family Relations 59(3):269-282.

Starks H, Brown Trinidad S (2007). Choose your method: A comparison of phenomenology, discourse analysis, and grounded theory. Qualitative Health Research 17(10):1372-1380.

The World Bank (2019). Literacy rate, adult total (\% of people ages 15 and above) - Ghana. Retrieved from https://data.worldbank.org/indicator/SE.ADT.LITR.ZS?locations $=\mathrm{GH}$ W

Thomas DR (2017). Feedback from research participants: are member checks useful in qualitative research? Qualitative Research in Psychology 14(1):23-41. doi:10.1080/14780887.2016.1219435

Wardlaw T, You D, Hug L, Amouzou A,Newby H (2014). UNICEF Report: enormous progress in child survival but greater focus on newborns urgently needed. Reproductive Health 11(1):82.

WHO (2006). Neonatal and perinatal mortality: country, regional and global estimates. In. Geneva: WHO.

WHO (2019). Maternal and perinatal health. Retrieved from https://www.who.int/maternal_child_adolescent/topics/maternal/mater nal_perinatal/en/

Wirihana L, Welch A, Williamson M, Christensen M, Bakon S, Craft J (2018). Using Colaizzi's method of data analysis to explore the experiences of nurse academics teaching on satellite campuses. Nurse Researcher 25(4):30.

Wonch Hill P, Cacciatore J, Shreffler KM, Pritchard KM (2017). The loss of self: The effect of miscarriage, stillbirth, and child death on maternal self-esteem. Death Studies 41(4):226-235. 